\title{
NARRATIVAS DE SI E SEXUALIDADES: OS USOS DOS ESPAÇOS DE ENSINO
}

\author{
Alexandre Luiz Polizel \\ Universidade Estadual de Londrina - UEL, Programa de Pós-graduação em Ensino de Ciências e Educação Matemática, \\ Londrina, PR. E-mail: alexandre_polizel@hotmail.com
}

\begin{abstract}
RESUMO
Este manuscrito tem por objetivo traçar considerações acerca da analítica dos usos de espaços de ensino pelos corpos LGBT. Para isso utiliza-se das teorizações heteroautobiográficas, sendo utilizadas um roteiro semiestruturado para guiar a produção de narrativas com seis jovens LGBTs, licenciandos na Universidade Estadual de Maringá, sul do Brasil. Após constituição de narrativa lançou-se mão do uso da analise de discurso sob ressonâncias Foucaultianas, utilizando como fio condutor desta analise os usos das espacialidades nos espaços de ensino. Nas narrativas os corpos LGBTs apresentaram que sua categoria identitária envolve quais espaços são passiveis de transito no espaço escolar, sendo evitados aulas de educação física, banheiros e a própria escola; em detrimento de outros espaços que estes procuram como aulas de teatro, literatura e grêmios escolares. Assim, vê-se que os regimes de normalidade posicionam sujeitos como passiveis de transitar em determinados espaços em detrimento de outros, eleição atravessada pelos caracteres identitários.
\end{abstract}

Palavras-Chave: Educação, Espaços de Ensino, Diversidade.

\section{SELF NARRATIVES AND SEXUALITIES: THE USE OF SPACE OF EDUCATION}

\begin{abstract}
This manuscript aims to draw up considerations about the analytical use of educational spaces by LGBT bodies. For this, heteroautobiographic theorizations are used, and a semi-structured script is used to guide the production of narratives with six young LGBTs, graduating from the State University of Maringá, southern Brazil. After the constitution of narrative, the use of discourse analysis under Foucaultian resonances was used, using as the guiding thread of this analysis the uses of spatiality in educational spaces. In the narratives the LGBT bodies showed that their identity category involves which spaces are passable in the school space, avoiding physical education classes, bathrooms and the school itself; to the detriment of other spaces that they look for as theater classes, literature and schoolmates. Thus, it is seen that the regimes of normality position subjects as passable to transit in certain spaces to the detriment of others, election crossed by the identitarian characters.
\end{abstract}

Keywords: Education, Teaching spaces, Diversity. 


\section{NOTAS INTRODUTÓRIAS}

Este manuscrito consiste em um recorte constituinte de uma investigação maior intitulada: Histórias, violências e desalojares: A trajetória de LGBTs nos espaços de ensino. Neste trabalho, tenho por objetivo traçar considerações acerca da analítica dos usos de espaços de ensinos por licenciandos que se (auto)identificam como Lésbicas, Gays, Bissexuais e pessoas trans (LGBTs).

Considero com Michel Foucault $(2015 ; 2014)$ que os espaços formativos consistem em espaços de produção e subjetivação de saberes. Estes saberes são produtos e producentes - em uma linha conjunta de predicação e proposição - de relações de poderes. Esta relação saberespoderes fundam-se e mantem-se operante a medida que instaura verdades em funcionamento.

Estas verdades estabelecem-se como regimes, regimes de verdades, que socializam e naturalizam modos de existir. Os regimes de verdade, neste sentido produzem diferenças e com isso estabelecem-se juntamente a uma norma vigente. Assim, a norma institucionaliza-se a medida que produz a diferença-desvio, o natural constituído pelo anormal... Neste sentido, a produção de saber-poder requer disseminação e, que os sujeitos componham-se e se assujeitem reiterando a operação deste regime de verdade. Destarte, a escola tem papel central na produção de sujeitos operantes de acordo com a norma vigente, à medida que esta organiza, analisa e elege saberes dados como formativos ou não - e a medida que elege saberes a serem disseminados e "formados" sujeitos, esta funda também modos de existir passiveis de serem vividos como legítimos e, os usados como parâmetro para manutenção da norma (os não passiveis).

Assim, a escola organiza um espaço afim de favorecer determinados aprendizados, eleitos como formativos, em detrimento de outros via processo de disciplinamento. A escola lança-se mão de dispositivos pedagógicos, envolvendo os discursos que serão veiculados e, não discursivos, como a organização arquitetural - do espaço-tempo. Carteiras em fileiras, seriações para acesso a diferentes saberes, tempos e espaços que pode-se ou não circular, tudo para uma melhor disciplina. Assim, a disciplina instaura um modus formativo que acentua capacidades, habilidades, saberes-poderes e verdades (FOUCAULT, 2014). Os usos do espaço-tempo modulam assim as experiencialidades e, com isto as relações com saberes-poderes-verdades (FOUCAULT, 2015; 2014; BUTLER, 2015).

Neste sentido Leandro Colling (2015) pontua que o dispositivo da sexualidade encontra-se alinhado a um sistema de (cis)heteronormativo, estabelecendo os modos de existir cisgênero e heterossexuais como norma vigente, valorizado, incentivado e naturalizado como modo de estar. Tal conformação dos espaços de ensino tem reiterado esta lógica de operação.

Assim, voltamos nosso olhar ao questionamento: Como as características identitárias de Lésbicas, Gays, Bissexuais deslocam as atuações destes sujeitos nos espaços de ensino. Para isso, organizamos este manuscrito em dois eixos: a) O relatar sobre si como percurso metodológico; e b) Identidades sexuais minoritárias e os usos dos espaços de ensino, trazendo considerações acerca das analíticas desenvolvidas no trajeto desta investigação.

\section{O RELATAR SOBRE SI COMO PERCURSO METODOLÓGICO}

Cacos... Pedaços que são parte constituinte. Aos trilhos das trajetórias de vida e educacionais busquei por narrativas de si e se fiz isto foi buscando relatos de formaçãoconstituição de corpos que não fazem parte da história convencional dos currículos narrados. Minha busca foi ao encontro de um corpo múltiplo de atravessamentos tidos como minoritários, ou seja, com características de significação identitária que atribuem a este corpo um território precarizado, uma atribuição localizada no desvio, um corpo que cumula características que são desvalorizadas pela normativa regente. Meu corpus de investigação, as narrativas que busquei consistiam em estudantes locados em cursos de licenciatura que se autoidentificavam como pertencentes a categoria de minorias sexuais (Lésbicas, Gays, Bissexuais, e pessoas Trans), que 
concordassem em compartilhar suas histórias e, que fossem estudantes da Universidade Estadual de Maringá (UEM), localizada no estado do Paraná.

Busquei então sujeitos por conveniência, em grupos da Universidade, em grupos de estudo sobre as temáticas de gênero e sexualidades e, nos movimentos sociais estudantis. O convite era realizado aos sujeitos - pessoalmente ou via redes sociais - e agendada uma entrevista, um momento de dialogo a sós em uma sala da universidade. Antes de iniciar o diálogo era apresentado um Termo de Consentimento Livre Esclarecido ${ }^{1}$, bem como as questões guias que guiariam o diálogo e a contação de suas narrativas de vida. Este diálogo que o que permitia a produção do que chamo de partituras.

Assim, estas partituras e diálogos não foram produzidos aleatoriamente ou ao acaso; elas foram produzidas com cuidado e carinho necessários para dar a tônica dessas pessoas LGBT, que responderam, em entrevista oral, à perguntas que funcionaram como guias numa conversa em que seus registros sonoros foram captados e posteriormente transcritos heteroautobiográficos (RAGO, 2013). Perguntas abertas, para direcionar a rememoração e serem respondidas relatando suas histórias: a) Frente as violências contra as minorias sexuais de gênero, temos desde agressões físicas, psicológicas à simbólicas. Sob tais aspectos e frente a sua história de vida, o que você compreende como violência? b) Em um cenário onde a evasão da educação básica de indivíduos LGBTs tem sido recorrente em nosso pais, você em sua passagem pela educação básica já sofreu violência? c) Poderia nos relatar histórias destas violências de vida e comentar se estas influenciavam no seu processo de ensino e aprendizagem e ocupação destes espaços de educação básica? d) Em um contexto de ensino superior, que você ocupa você acredita que a violência para com LGBTs tem sido ocorrente? e) Você como membro desta minoria sexual, já sofreu violência? De que forma essa ocorrência influenciou na sua relação com o lugar que você ocupa? f) No que toca a sua história de vida, frente aos apagamentos realizados no Plano Nacional de Ensino, qual sua sensação?

Desta forma, com a finalidade de intensificar a atenção, o registro e o (re)ouvir as memorísticas dos sujeitos utilizei de: a) Audiogravação, seguira de transcrição e destruição do áudio; e, b) Caderno de campo, que antes-durante-após o diálogo permitiram a anotação de percepções e sensações (RAGO, 2013; REGO; AQUINO; OLIVEIRA, 2006; CANTANI, 2006).

Este processo do narrar a si, de produzir estes cacos é um carreador de subjetividades, de mostrar suas marcas, recortes de um passado que ainda fazem-se presentes e são presentificados constantemente na produção do si. O narrar-se é também o inventar a si, o expor-se nos encontros com as tecnologias de poder que o constituíram, seja ferindo seu corpo ou resistindo a estes ferimentos. É esta exposição de suas experiencialidades que apresentam dor e valoração, representa formas e sentidos que são dados a própria vida. É um processo constitutivo, seletivo, de tradução, em que os significados não são os mesmos de antes, fazem-se significados outros e, são eleitos para serem narrados e registrados (FOUCAULT, 2015; RAGO, 2013; REGO; AQUINO; OLIVEIRA, 2006; CANTANI, 2006).

Aqui, apresento então os cacos, cacos produzidos de maneira heteroautobiográfica (RAGO, 2013), visto que estas autobiográfias que me são narradas atravessam meu corpo, fazem com que eu analise, traduza e escreva-as junto, com as minhas mãos e, com as tecnologias de poder que também atravessam meu eu. Arrisco a minha tecnologia de ouvir e de olhar a este trabalho, a hermenêutica que utilizo, a analise discursiva inspirada em Michel Foucault e sua ressonâncias (2015; 2014; 1996; FISCHER, 2001), bem como a perspectiva heteroautobiográfica de Margareth Rago (2013).

Se faço isto, é estabelecendo uma valorativa ao olhar heteroautobiográfico como instrumento que entende a produção dos cacos como processos de múltiplas traduções, de um

\footnotetext{
1 Procedimento aprovado no Conselho de Ética e Pesquisa com Seres Humanos da UEM, sob no CAAE 55404015.5.0000.0104. Utilizamos de nomes fictícios afim de preservar a identidade dos sujeitos.
} 
encontro entre corpos durante a entrevista, a escuta, a leitura, a interpretação, a analise, a escrita... É no compreender a existência de um reconhecimento de precariedades nos encontros dos corpos que escutam-se e, entender que as traduções são também inscrições do nosso eu (RAGO, 2013). Eu decalco tecnologias de poder, vejo-as funcionar, apresento-as a medida em que meu corpo consegue reconhece-las e que o corpo que eu escuto também as reconhece-as e me enuncia. Assim, a heteroautobiografia é utilizada aqui, pelo seu pautar no reconhecimento, na escuta de si e do outro, no compreender as limitações da tecnologia do olhar e do ouvir e, no entender sua potencialidade para o estabelecimento de um campo do relato de si pautado no "reconhecimento" destas tecnologias de poder.

Assim, os cacos produzidos e apresentados aqui foram no encontro a seis corpos, atravessados por múltiplas categorias identitárias, um corpo:

a) Leila, "[...] 24 anos, negra, feminista interseccional, candomblecista, bissexual e licenciada em história";

b) Rafael, "[...] 20 anos, homossexual, afeminado, [...] acima do peso e [...] licenciando em química";

c) Gustavo, "[...] 20 anos, gay, gordo, afeminado e licenciando em biologia";

d) Jéssica, "[...] 25 anos, mulher, branca, feminista e lésbica [...] formada em psicologia";

e) Leticia, "[...] 24 anos, cursei pedagogia, sou negra, mulher e trans";

f) Luiza, "[...] 22 anos, me formei em artes cênicas na UEM [...] uma pessoa branca, não binária, e prefiro assimilar signos femininos ao invés de masculinos".

\section{IDENTIDADES SEXUAIS MINORITÁRIAS E OS USOS DOS ESPAÇOS DE ENSINO}

As narrativas apresentadas foram múltiplas, todavia estas encontram-se em duas consonâncias: a) serem agrupadas como categorias identitárias minoritárias, no que dizem respeito a suas sexualidades; e b) Consistirem em sujeitos licencia(n)dos em uma Universidade Estadual do interior do Paraná e, que se dedicam a área da docência. Dentre as narrativas, selecionamos como fio condutor, buscar como estes relacionam-se com os espaços pelos quais circulam.

Evidencia-se na composição dos cacos narrativos ao pensar os usos dos espaços de ensino "[...] influenciava em como eu ocupava os espaços (escolares)" (Gustavo), dois eixos analíticos: a) Evadir e evitar circulações em determinados âmbitos; e b) Constituir e ocupar espaços não convencionais.

No que toca a evasão e evitar circulações em determinados âmbitos, vê-se como exemplo que estes "[...] não era bem vinda nesses espaços" (Leila), "[...] não fazia aula da educação física, arrumava atestados semestrais para não perder nota" (Gustavo), e até mesmo se ocupava os espaços "[...] não gostava de chamar atenção" (Jessica). Evidencia-se que os estudantes evitavam espaços por medo de não serem tratados como iguais, ou serem lidos como reconhecidos como "[...] pessoas normais" (Rafael).

Vê-se que os espaços educacionais são atravessados por políticas de normalidade. Estas vertem-se sob os corpos classificando-os como passiveis ou não de ocuparem estes espaços e, passiveis ou não de poderem representar-se e produzir enunciados nos campos de produção e aprendizados de saberes (FOUCAULT, 2015; 2014; 1996). Os sujeitos LGBTs que narraram-se, apresentavam como considerações que o que levavam a este evitar tais localizações estavam relacionados a sua identidade sexual.

Rafael e Gustavo, ambos homossexuais e "[...] gordos" (Gustavo), evitam espaços que envolvem contato físico, como as aulas de educação física. Estes fazem isto com o intuito de preservarem sua integridade física, pois acreditam que por serem lidos como sujeitos afeminados estes poderiam ter seus corpos violados durante aulas que envolvem "[...] contatos" (Rafael). O evitar determinados locais, levam estes a buscar outros espaços ocupáveis por seus corpos, 
buscando assim ocupar aulas de teatro, bibliotecas e, espaços de atuação filantrópicas nas instituições de ensino.

Leila, vê-se deslocada pelo fato de ser uma menina bissexual e negra em um colégio confessional privado - onde era bolsista -, esta evita as aulas, buscando nestas fugas articular-se com estudantes de escolas públicas. Suas buscas dão-se nos arredores destas e, em praças, onde reúne-se com outros estudantes.

O que evidencia-se neste sentido é a busca por espaços em que seu corpo é autorizado a ocupar, existir e experienciar. Espaços em que seu corpo gay e bissexual transita e é reconhecido (FOUCAULT; 2014; BUTLER, 2015). A busca por espaços de acolhimento, neste sentido, é a busca por firmar-se como um modo de existência legitimo e passível de ser vivido. É a busca por uma experiencialidade em que sua vida importa. O sistema normativo (FOUCAULT, 2015; 2014; 1996) não exclui a diferença, ele necessita desta e, para isso, ele precisa de espaços que esses corpos ocupem.

Jéssica também evita os espaços das aulas de educação física, visto que não são lidos como espaços "[...] destinados a meninas". Seu ato de resistência, reside então no ocupar estes espaços escondido durante o ensino fundamental. No ensino médio, sua estratégia é deslocada e essa passa a interagir com as instancias políticas de representatividade estudantil, articulando-se a atuação do "[...] grêmio estudantil".

Luiza e Letícia, como lidas em um espectro de transição dos espaços de gênero, ou seja, lidas e (auto)identificadas como mulheres trans, encontram resistência em espaços delineados pela categoria sexo - representada por discursividades biológicas. Estas veem resistência em viagens nas quais são alocadas em quartos juntamente com meninos, nas proibitivas dos usos do banheiro e, na negação de perspectivas de ocupação de espaços de poder. Luiza tem problemas também no teatro, sua área de atuação, visto que "[...] quando se está em um corpo masculino e tem que interpretar personagens femininas, e você tem pelos, você tem pomo de adão, as pessoas não vão acreditar que aquele personagem é uma mulher; e para fazer um homem, não se sentir à vontade", ou seja, em seu próprio campo de atuação cidadã e profissional. Estas, entretanto, não evadem dos espaços convencionais de ensino, mas sim buscam ocupa-los e reiterar que seus corpos tem direitos de ocupar aqueles. Estas atuam no embate pelo direito de ocupar espaços educacionais.

Vê-se, aqui, que Jéssica, Leticia e Luiza apresentam comportamentos semelhantes. A início estes buscam ocupar os lugares que não lhes são autorizados as escondidas. A proibitiva não evita que determinados modos de existir aconteçam, pelo contrário, necessitam da violação da proibição para que esta reforce-se como necessária (NIETZSCHE, 1974). Todavia, no ensino médio e superior a estratégia modifica-se, passam a requerer sua existência em espaços em que estes incomodam - por não serem autorizados no discurso oficial deste - e ao fazerem isto não buscam outros espaços de escuta (BUTLER, 2015), mas sim em transformar, deslocar, tracionar e reinventar os regulamentos dos espaços já existentes. Não trata-se aqui de buscar outros espaços de acolhimento e aceitação, mas de ocupar os espaços e mudar as ecologias destes, fraturando as normativas. Para Jéssica, Leticia e Luiza não bastam outros espaços de acolhimento, mas transformar espaços que lhes são legados em Outros, abrindo-os para a diversidade, diferença e pluralidade. Friedrich Nietzsche (1974) trata este agir como uma ecologia de cenários não adoecidos pelo ressentimento. Ecologia possível apenas quando este abre-se as diferenças e reconhecem-nas, ao invés de teme-las.

\section{CONSIDERAÇÕES}

Evidencia-se que os espaços de ensino são constituídos por múltiplas localidades passiveis de ocupação. Os sujeitos assim são posicionados, de acordo com suas categorias identitárias como passiveis ou não de ocupa-los - de acordo com uma normatividade vigente. Vê-se assim que as 
narrativas mostram-se como um modus de revisitar as trajetórias de vida dos sujeitos durante sua passagem pelos espaços de ensino e, identificar como suas categorias identitárias negociavam com os usos dos espaços.

Percebe-se que os corpos LGBTs evitam espaços de contato físico e, que reiteram padrões de normalidade. Destaca-se nas falas dos seis sujeitos que narraram-se que os principais espaços que levavam desconforto em ocupação consistiam nas aulas de educação física, dormitórios, banheiros e na própria instituição escolar enquanto espaço. Vê-se que os corpos gays e bissexuais ouvidos, operavam pela lógica de evitar locais que pudessem atentar contra sua saúde física e mental, buscando outros espaços para ocupar como aulas de teatros, bibliotecas, projetos de extensão, praças e outras escolas. Estes operam pela busca de outros espaços em que seus modos de existir são passiveis de serem vividos e escutados - espaços de acolhimento. Os sujeitos que (auto)identificam-se como travestis, operavam por outro agir, sendo que durante o Ensino Fundamental ocupavam espaços que não Ihes era permitido as escondidas e; no Ensino Médio e Superior, ocupavam espaços que não Ihes era permitido reivindicando que este fosse um espaço de escuta e de reconhecimento de sua resistência - requeriam uma ecologia outra, um novo estatuto de uso destes espaços, vertendo-os a abertura para as diferenças.

\section{REFERÊNCIAS}

BUTLER, J. Relatar a si mesmo: crítica à violência ética. Belo Horizonte: Autentica Editora, 2015

CATANI, D.B. Autobiografia como saber e a educação como invenção de si. In SOUZA, E.C.; ABRAHÃO, M.H.M.B. (Orgs) Tempos, narrativas e ficções: a invenção de si. Porto Alegre: EdiPUCRS, p.77-87, 2006

COLLING, L. O que perdemos com os preconceitos? Revista Cult, 202, ano 18, p. 22-25, 2015

FISCHER, R.M.B. Foucault e a análise de discurso em educação. Cadernos de Pesquisa, (114), 2001, p.197-223

FOUCAULT, M. A ordem do discurso. São Paulo: Edições Loyola, 1996

. Vigiar e punir: Nascimento da prisão. 42 ed. Petrópolis-RJ: Vozes, 2014

. História da sexualidade I: A vontade de saber. 3 ed. São Paulo: Paz e Terra, 2015

NIETZSCHE, F. Obras incompletas. São Paulo: Abril Cultural, 1974

RAGO, M. A aventura de contar-se: Feminismos, escrita de si e invenções da subjetividade.

Campinas, SP: Unicamp, 2013. https://doi.org/10.7476/9788526814691

REGO, T.C.; AQUINO, J.G.; OLIVEIRA, M.K. Narrativas autobiográficas e constituição de subjetividades. In: SOUZA, E.C. (Orgs). Autobiografias, histórias de vida e formação: pesquisa e ensino. Porto Alegre: EdiPUCRS, 2006, p. 269-286 